\title{
REPRESENTAÇÕES DA HISTÓRIA DA GUERRA DE LA TRIPLE ALIANZA NO REGIME DE STROESSNER
}

\author{
REPRESENTATIONS OF THE HISTORY OF THE GUERRA DE LA TRIPLE ALIANZA \\ IN THE STROESSNER REGIME
}

Bruna Reis Afonso*

\begin{abstract}
Resumo: Este trabalho procura analisar a construção da narrativa sobre a Guerra da Tríplice Aliança (1864-1870) durante o regime Stroessner. Alfredo Stroessner governou o Paraguai de 1954 a 1989. Dentre as estratégias para legitimar-se no poder fez uso de um discurso fortemente nacionalista, mobilizando a história através do resgate da memória dos grandes heróis nacionais, principalmente a de Solano López, considerado o grande herói da Guerra. Considerando a mobilização da história de maneira a justificar o regime e os aportes feitos no sistema educacional, os manuais escolares configuram-se como fontes privilegiadas para compreender a história da guerra ensinada aos jovens no período, bem como, as projeções sobre passado, presente e futuro que permeiam a narrativa escolar acerca do evento.
\end{abstract}

Palavras-chave: Manuais escolares. Guerra da Tríplice Aliança. Regime Stroessner. Nacionalismo.

\begin{abstract}
This article analyzes the construction of the narrative about the War of the Triple Alliance (1864-1870) during the Stroessner regime. Alfredo Stroessner ruled Paraguay from 1954 to 1989. Among the strategies to legitimate himself in power, he used a strong nationalist discourse, rescuing the memory of great national heroes, mainly Solano Lopez, regarded as the largest war hero. Considering the mobilization of history to justify the regime and contributions in the educational system, textbooks are privileged sources for understanding the war's history taught to young people in the period and the projections about the past, present and future that sourounded the school's narrative about the event.
\end{abstract}

Keywords: Textbooks. War of the Triple Alliance. Stroessner regime. Nationalism.

\footnotetext{
* É bolsista Capes e estudante do curso de Mestrado do Programa de Pós-graduação em História da UFMG.

E-mail: brunareisafonso@gmail.com.
} 


\section{Introdução}

Este trabalho procura analisar a narrativa sobre a Guerra de la Triple Alianza ou Guerra do Paraguai (1864-1870) durante o regime Stroessner no Paraguai (1954-1989). A Guerra da Tríplice Aliança tem raízes na crise política que se instaurou na região platina, na década de 1860, momento em que Paraguai e Uruguai uniram seus interesses contra a política intervencionista adotada pelos dois grandes vizinhos, Brasil e Paraguai. O Uruguai, vivIa sob a disputa política entre os blancos, do presidente Bernardo Berro, e os colorados, de Venancio Flores. Em 1864, o Brasil invadiu o Uruguai em apoio a Venancio Flores. A intervenção brasileira foi compreendida pelos paraguaios como um ato de guerra e, em represália, Solano López mandou aprisionar o navio Marquês de Olinda, que navegava por águas paraguaias, levando a bordo o novo presidente da província de Mato Grosso.

A guerra teve grande impacto tanto nas relações internacionais entre os Estados que nela se envolveram, quanto na política interna dos mesmos. Vitor Izecksonhn (2009) destaca que a guerra desorganizou a vida política e institucional dos países beligerantes, exceto a Argentina, que teve como saldo a consolidação da centralização política.

O pós-guerra paraguaio foi marcado pela instabilidade política, golpes e guerras civis que culminaram na ascensão de uma das mais duradouras ditaduras latino-americanas, a saber, o regime Stroessner. Pode se dizer que a Guerra provocou uma ruptura na história política da república paraguaia, visto que o Paraguai se tornou independente em 1811, e a partir de então, sob a ditadura de Francia, adotou uma política centralizadora e isolacionista. Entre 1814 e 1864 o país foi governado por José Gaspar Rodríguez de Francia, Carlos e Solano López, apesar do autoritarismo o país vivia em relativa estabilidade política. Ceres Moraes destaca que "a reorganização Estado paraguaio [após a guerra] se deu num cenário de miséria e dominação estrangeira".(MORAES, 2000 p.13) As perdas materiais, culturais e sociais paraguaias marcaram de tal forma o país, que grande parte dos autores que escrevem sobre a história do Paraguai no século XX, veem-se impelidos a fazer referência ao conflito. Nidia Areces traz uma importante reflexão sobre a profundidade da repercussão que a história da Guerra ainda tem na sociedade paraguaia:

Habría que analizar en profundidad alguna cuestiones que atañen no solo a los elementos materiales, sino a los elementos de pertenencia identitaria, a las formas de hacer política y a las intencionalidades económicas. Y, sobretodo, enfrentarse a los contenidos y representaciones de un relato 
construido desde fines del siglo XIX, que se mantiene vigente y que sigue siendo referencial, porque cada uno conoce e interpreta los hechos de la guerra al mismo tiempo que impregna el espacio público y el imaginario colectivo, pivotes fundamentales de toda conformación identitaria que, al preguntarse sobre su futuro, se remonta a su pasado buscando respuestas que mucho tienen que ver con las experiencias históricas transmitidas por la sociedad paraguaya. La guerra en sí misma, la representación de sus vivencias, los relatos transmitidos de generación en generación, en simbiosis con el imaginario colectivo, enmarcan para el pueblo paraguayo una tragedia de inconmensurables dimensiones, cuyos significados difieren, resignificándose continuamente. La guerra ha impactado no solo la esfera político-ideológica, sino también en la de los sentimientos aguijoneando la conciencia que sin duda, tiene que dar lugar a seguir repensando y democratizando la escritura de la historia. (ARECES, 2014, p.. 194)

Para o Brasil, a Guerra possibilitou o fortalecimento dos militares, especialmente do Exército, mas o descumprimento das promessas realizadas aos Voluntários da Pátria acirrou os conflitos entre o exército e as classes dirigentes. A longa duração do conflito teve um alto custo também em termos financeiros e sociais. Os soldados brasileiros, em sua maioria, eram homens despreparados para a guerra, mal treinados, com alimentação precária, morreram não só em combate, mas também devido à fome, à doenças - a cólera, a varíola e a malária assombraram os combatentes - e às intempéries (DOURADO, 2010). Em contrapartida, o conflito teve papel crucial na construção da identidade nacional, de acordo com José Murilo de Carvalho. “A guerra pôs em risco a vida de milhares de combatentes, produziu um inimigo concreto e mobilizou sentimentos poderosos. Indiretamente afetou a vida de boa parte dos brasileiros, homens e mulheres, de todas as classes, em todas as regiões do país." (CARVALHO , 2005 p. 179) Nesse sentido, a guerra teve maior relevância para a construção da identidade brasileira que a independência e a proclamação da República, como argumentou o autor. Outro historiador que coaduna com essa perspectiva é Mario Maestri (2008), que declara que a perspectiva nacional-patriótica da Guerra, que colocava os militares como os guardiões dos interesses nacionais, serviu à construção da identidade nacional republicana.

Em resumo, "qualquer que seja a perspectiva a Guerra da Tríplice Aliança foi um marco. Um acontecimento histórico de pesadas consequências, que daria nova dimensão à história dessa parte do planeta." (MOTA, 1996, p. 244). Com efeito, a história da guerra tem passado por intensos debates e revisionismos ao longo do século XX. 
Alfredo Stroessner Matiauda (1912-2006) governou o Paraguai desde 1954 até 1989. Durante seu governo ocorreram duas importantes reformas educacionais com o apoio da Unesco, em 1957, e da USAID- Agência Norte Americana para o Desenvolvimento Internacional -, em 1973, ambas provocaram modificações profundas na estrutura do sistema educacional paraguaio.

Tendo em vista a mobilização da história de maneira a legitimar o regime, principalmente, a história da Guerra de 1864-1870, bem como os aportes e modificações feitos no sistema educacional, os manuais escolares configuram-se como fontes privilegiadas para compreender a história da guerra ensinada aos jovens no período, bem como, as projeções sobre passado, presente e futuro que permearam a narrativa oficial sobre esse evento. A fim de compreender as novas práticas educacionais fomentadas pelo regime analisaremos documentos normativos e grades curriculares produzidos durantes as duas reformas, bem como a bibliografia relacionada ao tema.

\section{O pós-guerra e as representações dos López}

É importante considerar que ao longo do século XIX e XX a história da Guerra de la Triple Alianza ou Guerra do Paraguai passou por vários revisionismos historiográficos. A fim de traçar um breve panorama destacaremos as diferentes perspectivas produzidas sobre a guerra no Paraguai. Após 1870 a política paraguaia foi marcada por grande instabilidade, lutas internas e graves problemas econômicos. Antes mesmo do falecimento do Marechal Solano López, presidente da República do Paraguai, em 1870, o governo provisório do país o declarou traidor da Pátria e fora dalei (DORATIOTO, 2002, p. 83); López passou a figurar na história oficial como "um ditador que lançou seu país em guerra imprudente contra vizinhos mais poderosos" (DORATIOTO, 2002, p. 79). Thomas Whigham ressalta que

los detractores paraguayos del mariscal, quienes mayormente se afiliaron al Partido Liberal desde fines del siglo diecinueve, lo consideraban un monstruo sin igual cuya vanidad exigió la extinción de su pueblo. En su mundo en blanco y negro, lo pintaron más oscuro que la oscuridad, y a sus seguidores como simples estúpidos o bárbaros. (WHIGHAM, 2012, p. 502)

Essa representação negativa de López, entretanto, não era consensual, mesmo no pós guerra e durante os anos de hegemonia do Partido Liberal ainda havia aqueles que enxergavam o Mariscal de maneira distinta. Eram estudantes secundaristas e universitários 
"que desejosos de construir uma sociedade melhor (...), necessitavam de heróis que encarnassem os valores, supostos ou verdadeiros, da nacionalidade paraguaia" (DORATIOTO, 2002, p. 80) e camponeses que falavam guaraní, espalhados em diversos pontos do país seguiram cultuando a imagem de López.

Após 1870, a política paraguaia, antes marcada pela estabilidade, entrou em um ciclo de ferrenhas disputas políticas que, por vezes, culminaram em guerras civis. Na década de 1880 fundaram-se os dois partidos tradicionais, o Centro Democrático (1887) que mais tarde transformou-se em Partido Liberal e a Associação Nacional Republicana (1887), conhecido popularmente como Partido Colorado. O primeiro agrupou jovens intelectuais e camponeses expropriados descontentes com os caudillos que controlavam o governo. O segundo agrupou os terratenentes e militares conservadores sob a liderança de Beranardino Caballero "um dos oficiais mais aguerridos de López”. (ARCE, 1988, p. 225).

As disputas políticas entre os dois partidos culminaram em um movimento armado que ficou conhecido como Revolução de 1904 ou Revolução Liberal, que contou com o apoio dos argentinos, camponeses e operários, da qual os liberais saíram vitoriosos. Vale ressaltar que os liberais também eram profundamente anti-lopistas.

Em junho de 1932 o Paraguai entrou em conflito com a Bolívia, dando início a Guerra do Chaco (1932-1935), de acordo com Ceres Moraes "a Guerra do Chaco e seu desenlace criaram, no Paraguai, uma situação revolucionária, que serviu para unir, num mesmo movimento todas as correntes antiliberais" (MORAES, 2000, p.27). Lorena Soler (2007) argumenta que a Guerra do Chaco fomentou um nacionalismo na sociedade paraguaia, com diversas correntes, desde as fascistas, até aquelas que reivindicavam direitos sociais e políticos. Nesse contexto, os militares tornaram-se os atores políticos que poderiam melhor representar a nação, assim, na década de 1930, surgiu o movimento Febrerista encabeçado por militares nacionalistas e que haviam saído vitoriosos da guerra. Assim, a vitória paraguaia na Guerra do Chaco abriu caminho para olhares heroicos para o passado militar e os manuais de história voltaram a ser reescritos para contar que foram declarados próceres beneméritos José Gaspar de Francia, Carlos López e Francisco Solano López..

Lorena Soler ressalta que na década de 1920 eclodiram movimentos de caráter nacionalista e antiliberal em diversos países da América Latina e da Europa, este período é marcado pela busca das raízes culturais e sociais da nação, do originário, do autóctone, tendo como objetivo a construção da identidade nacional. É em busca das origens da nação 
paraguaia que Rafael Franco, presidente do Paraguai entre 1936 e 1937, criou uma expedição que foi a Cerro Corá na tentativa de resgatar os restos mortais de Solano López, segundo os relatos dos expedicionários o caminho foi facilitado pelas sinalizações que os soldados paraguaios inscreveram em guaraní nas cascas das árvores. Tais relatos permitiram fundir dois símbolos da paraguaidade, a língua guaraní - que passa a figurar como elemento originário do país - e Solano López, o herói da pátria (SOLER, 2007). Foi neste contexto que o Panteón Nacional de los Heroes foi edificado no mesmo local destinado ao culto a Vigem de Assunção, que havia sido construído em 1863, durante o governo Solano López. No Panteón repousam os restos mortais daqueles que foram considerados os grandes heróis da pátria.

Do ponto de vista historiográfico, Liliana M. Brezzo divide a produção paraguaia em cinco momentos. Destacamos três que por terem produzido interpretações mais elaboradas sobre a História da Guerra do Paraguai. Brezzo destaca que nos primeiros anos do pós-guerra a história tornou-se campo de observação privilegiado para os intelectuais paraguaios que ficaram conhecidos como novecentistas. Para essa geração de intelectuais a guerra representou um momento de "resistência empenhadíssima e sobre-humana" (BREZZO,2009, p.66). Esta abordagem procura ressaltar que durante o governo de Carlos López o país viveu sua "Idade do Ouro", sendo uma das maiores "potências militares" da América do Sul, tendo grande desenvolvimento econômico.

O segundo momento historiográfico foi marcado pela disputa entre Cecílio Báez e Juan O'Leary. Báez produziu uma forte crítica aos governos de Francia e dos López, denunciando a tirania e responsabilizando-os pelo embrutecimento do povo como também pela Guerra de 1864-1870. Já O'Leary propôs uma história patriótica, na qual a guerra, em lugar de ser vista como um desastre, tornou-se epopeia nacional.

Na década de 1930, a vitória na guerra do Chaco e a chegada dos Febreristas ao poder impulsionaram os estudos históricos. Nesse período a história patriótica de O'Leary tornou-se história oficial da Guerra do Paraguai, é dizer que, José Gaspar de Francia, Carlos Antonio López e Francisco Solano López passaram a figurar como próceres beneméritos da história do Paraguai. Essa perspectiva, que apresentou a Guerra do Paraguai como ruptura de uma história próspera, autônoma e estável, consolidou-se durante o regime Strossner, no qual passou a ser veiculada para o grande público através de livros didáticos e também pelos principais jornais paraguaios, que com o recrudescimento da ditadura passaram a produzir 
extensas reportagens sobre o Dia de los Heroes- em que se homenageia Solano López por ocasião de seu falecimento, em 01 de março de 1870 - e sobre a guerra. ${ }^{1}$

\section{Ascensão de Stroessner}

No dia 04 de maio de 1954, um movimento militar comandado pelo General Stroessner, depôs o então presidente Frederico Chávez. Stroessner não assumiu imediatamente o poder, o partido Colorado indicou como presidente provisório Tomás Romero Pereira, que marcou eleições para o dia 12 de julho. Stroessner tornou-se presidente do Paraguai pelas vias legais, apesar de a eleição ter apenas ele como candidato

Stroessner manteve-se no poder por 35 anos, seu governo durou mais que ditadura de Francia (26 anos) e que o governo dos López (28 anos). A longevidade do regime Stroessner deve-se a uma conjuntura externa e interna favorável. Com um discurso fortemente anticomunista, Stroessner, recebeu apoio dos Estados Unidos, por meio de financiamentos e empréstimos, bem como do governo brasileiro. Desde a década de 1940, o Paraguai passava por uma onda de intensa instabilidade política, marcada pela violência e pelo agravamento da crise econômica e das condições de vida da população:

Quizás por eso, importantes segmentos políticos del país acepataron como um mal menor el advenimiento de una mano militar que pusiera fin al desorden político y pacificara la República. Stroessner, um descendiente de alemanes de 41 años de edade, gozaba de um relativoo prestigio em esferas militares y parecía ser la persona indicada. (BOCCIA, Alfredo. 2003, p. 53).

De acordo com Myrian Gonzáles Vera (2002) é provável que a longevidade do regime deva-se ao uso constante da repressão e do terror, que conseguiu desmobilizar e paralisar as forças opositoras. O Partido Colorado também foi uma ferramenta importante para a consolidação do regime, o partido tinha uma base nacional ampla e através de suas seccionais ou subseccionais criou-se uma estrutura de clientelismo, espionagem e delação.

\footnotetext{
${ }^{11}$ Vale salientar que o Triunvirato que governou o Paraguai a partir de 1869, declarou Solano López traidor da Pátira, bem como qualquer "cidadão que continuasse a servir o tirano". Somente, em 1936, com a ascensão do Partido Revolucionário Febrerista, sob a liderança de Rafael Franco, é que López foi elevado à categoria de herói nacional; C.f. (WHIGAN, 2015, p. 1112).
} 
Para ser funcionário público era necessário afiliar-se ao Partido, assim a estrutura partidária incorpora milhares de cidadãos que recorriam as seccionais em busca de favores. Stroessner também fomentou o culto a sua imagem, ruas, praças, bairros, o Aeroporto Nacional de Assunção e a segunda maior cidade do país foram denominadas Presidente Stroessner (GONZÁLEZ, 2002). Stroessner também procurou colocar-se como sucessor dos heróis da nação difundindo a ideia de que viera para trazer a paz e o progresso, assim como o fizeram os grandes heróis do passado, isto é, Francia e os López.

\section{Reformas educativas e práticas escolares durante o regime Stroessner}

O advento do governo de Alfredo Stroessner promoveu transformações políticas sociais e econômicas profundas no Paraguai, que incidiram também no âmbito da educação. De acordo Oscar Pineda (2012), com a ascensão de Stroessner a educação se politizou rapidamente, tornando-se um ambiente fecundo para a dissidência política, bem como alvo da ação repressiva do governo.

Ao analisar os impactos do stronismo nas práticas e mecanismos de regulação e repressão nas instituições escolares, Lorena Soler (e outros) ressalta que o regulamento das escolas primárias produzido, em 1964, era fortemente autoritário e "sancionaba la insubordinación, las acciones colectivas (como las huelgas) y la pluralidad o diversidad de ideas, definidas como promoción de la "disidencia". (SOLER et al, 2015, p.22). A perseguição política e a repressão aos indivíduos dissidentes no Paraguai era institucionalizada, atingido docentes e estudantes ligados ao partido Comunista, Liberal, Febrerista, mas também aqueles participavam de protestos, como demonstra o decreto 7560 , de 16 de setembro de 1954, que suspendeu por tempo indeterminado vários docentes das escolas da Capítal (Assunção) por se solidarizarem com atos de indisciplina universitária, o que demonstra o caráter marcadamente autoritário do governo de Stroessner já em seus primeiros meses de existência.

Durante o stronismo foram implementadas duas reformas educativas. A primeira, voltada para o ensino secundário, iniciou-se em 1956, com a mediação da Unesco e foi denominada "Reforma de 1957". Esta reforma da "Enseñanza Media" aspirava "elevar el nível cultural del pueblo paraguayo"(HORAK s/d, p.111) e a "una educación moderna, democrática y activa" (BENÍTEZ: s/d, 148), dentro dessa proposta foram criados os Centro de Alfabetização com a finalidade de promover um "programa intensivo de educación de jovenes 
e adultos" (Idem, 152), além de Centros Regionais da Educação, que foram planejados para serem centros de referência educacional no interior do país e tinham como principal objetivo a formação de docentes, além de oferecer ensino de alta qualidade em todos os níveis (Soler, 2015).

No bojo dessas transformações a Constituição de 1967 tornou a educação primária obrigatória, pública e gratuita.

\begin{abstract}
Artículo 89.- Todos los habitantes tienen derecho a la educación para desarrollar sus aptitudes espirituales y físicas, formar su conciencia cívica y moral, y a capacitarse para la lucha por la vida. La enseñanza primaria es obligatoria y se consagra la libertad de impartirla. El Estado sostendrá las necesarias escuelas publicas para asegurar a todos los habitantes, en forma gratuita, la oportunidad de aprender, y propenderá a generalizar en ellas, por los medios a su alcance, la igualdad de posibilidades de los educandos. También sostendrá y fomentará, con los mismos criterios de igualdad y libertad, la enseñanza media, vocacional, agropecuaria, industrial y profesional, y la superior o universitaria, así como la investigación científica y tecnológica.
\end{abstract}

Em 1969, o Ministerio de Educación y Culto publicou um diagnóstico do sistema educativo, no qual conclui que a "capacidad de absorción del sistema educativo a nível primário es insuficiente para hacer frente a la fuerte presión demográfica, sobretodo em los grados inferiores." (MINISTERIO DE EDUCACION Y CULTO 1969, tomo I, p.153) assim como também era insuficientes o mobiliário, os materiais didáticos, dentre outras deficiências.

Em 1969, foi publicado também o Plan de Desarrollo Educativo para o período de 1969-80, alguns dos principais objetivos eram:

a. Elevar el nível técnico-profisional y cultural de la población paraguaya;

b. Preparar a los alumnos, desde la enseñanza primaria, para que puedan participar como elementos activos em el proceso de desarrollo socioeconômico nacional

c. Formar mano-de-obra calificada, técnicos y profesionales que demande la ejecucion de la política nacional del desarrollo economico y social. [...] (MINISTERIO DE EDUCACION Y CULTO 1969, tomo II, p.07).

Em 1973, o Ministerio de Educacion y Culto publicou as Innovaciones Educacionales, documento que orientava a reorganização do currículo. Essa reforma do currículo definiu que um dos objetivos da educação primária era que a criança “conozca los hechos relevantes de la 
historia nacional, honre y respete las grandes figuras de la patria, desarrollando un patriotismo inspirado en el pasado, afincado en el presente y proyectado al futuro (...)." (MINISTERIO DE EDUCACIÓN Y CULTO,1973, p. 22). Já o estudante de nível médio deveria afirmar "una actitud positiva hacia el sentimiento de paraguayidad, que lo lleve a conocer, a respetar y amar su historia, sus riquezas naturales y artísticas, su cultura y tradiciones y se convierta él mismo en un promotor del incremento del patrimonio nacional" (Idem, 54).

O decreto 20.976, de fevereiro de 1976, estabeleceu como obrigatória a cerimônia de içamento da bandeira nacional e o canto do Hino pátrio..

Considerando que uno de los objetivos de la educación paraguaya es el de formar $\mathrm{y}$ fortalecer un sano $\mathrm{y}$ autentico patriotismo basado en el conocimiento de la gloriosoa historia nacional, que permita apreciar los altivos valores que representan los simbolos de la Nación y, al mismo tiempo venerar y exaltar la personalidad de los proceres y hereoes que nos lograron una Patria libre y soberana. El presidente de la República del Paraguay DECRETA:

art. $1^{\circ}$ ) Establécese como uma norma obligatória para todas las instituiciones de enseñanza primaria, media y de formación docente, oficiales y privadas de la República, la realización diaria de la cerimonia de izamento de la Bandera Nacional y el canto del Himno Patrio, por todos los profesores y alumnos presentes. [...] (Diário Pátria, 01 de março de 1976).

Os Programas de Estudio - Professorado de Educación Primáraria, documento publicado em 1983, ressalta que ao serem estabelecidas as bases para educação nacional o Ministério de Educación y Culto levou em consideração a natureza do homem paraguaio, a cultura paraguaia e "A la realidad nacional en su triple dimensión histórica: la de su pasado enaltecido por el ejemplo de sus héroes y prohombres, la de su presente comprometido con el proceso de su desarrollo y la de su futuro optimista y promisor (...)" (MINISTÉRIO DE EDUCACIÓN Y CULTO, 1983,p.13). Essa compreensão da história nacional , bem como a preocupação em construir uma visão positiva e patriótica do país, esteve presente em toda a estrutura curricular, por exemplo O Guia didático dos manuais de Estudos Sociais da Serie Nanduti, produzida pelo Ministerio de Educación y Culto, oferece sugestões metodológicas para que o professor estimule o patriotismo através de atividades propostas aos alunos que devem “(...) Leer biografías de patriotas, héroes, gobernantes, científicos y escritores nacionales. Destacar su contribución en la formación de la conciencia nacional". (MINISTÉRIO DE EDUCACIÓN Y CULTO,1989, p.57). Além de "participar en actos 
conmemorativos sobre los Símbolos Nacionales. Además pueden escribir poesías dedicadas a la bandera, el escudo, a fin de exaltar el nacionalismo paraguayo." (idem).

No cerne das reformas havia a necessidade de expandir o acesso a uma educação comprometida com a formação de mão-de-obra qualificada, que era uma das condições para o desenvolvimento do país. Ademais, desejava-se também que a escola fosse um ambiente de construção de um nacionalismo, um sentimento de paraguaydade e patriotismo.

\section{A história da guerra e o resgate dos heróis nacionais}

Neste artigo procuro analisar manuais utilizados no sistema educacional paraguaio destinados ao ensino primário e a etapa básica do nível médio. De acordo com o guia didático da Série Ñanduti "el libro de texto es uno de los recursos didácticos que contribuyen al desarrollo del currículum y, específicamente en el área de Estudios Sociales, a la formación del hombre en su dimensión individual y social, con miras a convertirlo en un miembro útil y efectivo de la sociedad en que actúa(...)” (MINISTERIO DE EDUCACIÓN Y CULTO, 1989, p.15). Assim, o manual escolar é um recurso pedagógico que não tem apenas uma função didática, mas também a de formar o ser humano, neste sentido, os discursos por ele veiculados extrapolam o âmbito escolar.

Juan José Carreras e Carlos Forcadell (CARRERAS. FORCADELL, 2003) ao refletirem sobre os usos públicos da história chamam atenção para o uso político da história:

De todos los usos públicos de la historia el político es más determinante, pues permea todos los demás, en sus formas más extremas, es el que degrada a historia, transformándola en historia meramente instrumental, sin más razón que su utilidad para ser usada. Es, por tanto, este de los usos públicos de la historia un tema estrictamente histórico y que como tal ha de ser analizado y entendido. (CARRERAS. FORCADELL, 2003, p.14).

Neste trabalho a escola é pensada como um lugar onde se efetiva o uso público e também político do passado. Luciana Pessanha Fagundes destaca que o passado deve ser visto como uma construção, portanto, seu sentido se altera com o tempo. "Narrativas sobre o passado são construídas com uma linguagem e um sistema de representação do presente" (FAGUNDES, 2010, p.03). Os usos políticos do passado, considera a autora, não são fortuitos ou aleatórios, são instrumentais. 
Serge Berstein salienta a importância dos vetores pelos quais passa a integração da cultura política. Dentre eles está o sistema de ensino, "a escola, o liceu a universidade" escola pode ser analisada a partir de diferentes enfoques, recortes temporais e teóricos, que buscam salientar aspectos sociais, pedagógicos, políticos ou culturais. A perspectiva adotada neste trabalho busca apreender a escola como uma das instituições difusoras de culturas políticas e, especialmente, o livro didático como fonte primária privilegiada para análise das representações da Guerra do Paraguai repercutidas no âmbito escolar. Nesse sentido, o manual escolar é compreendido como o lugar onde se materializa o discurso pedagógico e histórico sobre a Guerra.

O livro didático Estudios Sociales - primer curso da Série Nandut, destinado a etapa básica do nível médio - publicado em 1989 pelo Ministerio de Educación y Culto - no capitulo intitulado "Gobierno de Don Carlos Antonio López" apresenta o governo de Carlos López como responsável pelo progresso do país, assim o Paraguai figurava entre os melhores da América do Sul . Em seu governo houve desenvolvimento econômico e intelectual do Paraguai através da vinda de técnicos europeus. Nesta época, a história prometia ter "porvenir brillante para el Paraguay. Desgraciadamente la guerra del 64-70 truncó casi todas las ilusiones, sueños y realidades del Paraguay y sus hijos tuvieron que empezar de nuevo la reconstrucción de la Patria. (ALDERETE; TESSADA: 1989: 167).

Após abordar os costumes na época de Carlos López as autoras elaboraram algumas atividades de síntese e pesquisa acerca do conteúdo, chama atenção uma questão na qual pede-se que o aluno leia e comente alguns textos pequenos, sendo que o primeiro deles, atribuído a Luis Echeverría, descreve Carlos López como uma criança cujas "diversiones eran los libros, sus juegos era los libros, permaneciendo años enteros en su vida estudiosa, retirada y contemplativa. Su conducta como joven a los viejos asombraba." (idem, p.169). A narrativa mitifica desde a infância a figura de Carlos López destacando sua maturidade e dedicação aos estudos, daí sua preocupação com o desenvolvimento intelectual do país quando presidente, bem como sua habilidade no campo diplomático, elementos que serão evidenciados em capítulo posterior.

\footnotetext{
${ }^{2}$ BERSTEIN, Serge. A Cultura Política. In: RIOUX \& SIRINELLI (Org.) Para uma História Cultural. Lisboa: Estampa, 1988. P. 356
} 
O capítulo sobre o governo de Francisco Solano López inicia abordando o processo de sucessão do governo. Em diversos manuais escolares e livros de historiadores paraguaios aparece o relato de que antes de morrer Carlos Antonio López teria dito ao seu filho mais velho, Francisco Solano, "Hay muchas cuestiones pendientes a ventilarse, pero no trate Ud. De resolverlos con la espada sino con la pluma, principalmente con el Brasil" (idem, 170), o manual, entretanto, não esclarece que questões eram essas e em seguida questiona sobre o significado deste ultimo conselho de Carlos López, assim, o estudante deve buscar a informação e justificar sua resposta.

Outra demanda interessante é que o estudante pesquise sobre a biografia de Solano López e mencione três aspectos que mais lhe causaram admiração. Este questionamento é seguido por um pequeno texto de caráter biográfico sobre López, no qual destaca-se que ele foi o maior colaborador de seu pai, era "Dinámico y estudioso, adquirió formación intelectual mediante preceptores particulares y una rica biblioteca; hablaba y escribía correctamente el francés y el inglés, y con fluidez y elocuencia el guaranî” (idem, p. 171). Solano López é apresentado como alguém que conhecia outras culturas, um homem de letras, mas que não se apartava das origens da cultura paraguaia, isto é, a língua guaraní.

Em relação a narrativa sobre a guerra, ressalta-se que foi congresso que declarou guerra contra a Argentina e que as questões ocorridas na região platina coincidiram com a época do governo de Solano López. Durante a guerra López “encarnó la suprema decisión paraguaya de no dejarse humillar.”. (idem, p.172).

Ao tratar das questões de limites com os países vizinhos, o manual ressalta que, em 1862, venceram os tratados de limites firmados com o Brasil e Argentina. Antes que os problemas em relação as fronteiras fossem resolvidos, brasileiros ocuparam a área neutralizada pelo tratado Berges-Paranhos (1856), construindo as cidades de Dourado e Miranda. Em relação a argentina a situação era ainda mais grave porque paraguaios exilados alentaram velhas pretensões portenhas de se apoderar do governo paraguaio. Assim ao citar as causas da guerra a primeira delas foi a ambição territorial do Brasil, seguida pela revolução de Venâncio Flores, equilíbrio dos estados do Plata. Vale ressaltar que as causas são apenas citadas, não se explica o processo que levou a guerra.

Tem grande relevância na narrativa o Tratado Secreto da Triplice Aliança, já que no documento dizia-se que "se debía respetar la independencia, soberanía e integridad territorial de la República del Paraguay, pero se disponía, al mismo tiempo, la desmembración 
territorial, el pago de los gastos de guerra y la indemnización correspondiente" (idem, p.176). A contradição apontada ratifica a ideia de que Brasil e Argentina ao entrarem na guerra tinham ambições territoriais em relação ao Paraguai. A partir dessa apresentação inicial da guerra, pergunta-se ao estudante sobre sua impressão em relação ao conteúdo do Tratado Secreto da Tríplice Aliança.

Ao tratar das principais batalhas da guerra, o manual ressalta que o "el armamento disponible era de modelo anticuado y muchos jefes no tenían preparación, pero palpitaban en el ambiente una gran fe, una fuerza moral y una disciplina férrea" (idem, p. 178). Dentre as batalhas mais memoráveis estão a de Humaitá, onde a luta se prolongou por três anos e a de Acosta $\tilde{N} u$ na qual “ Para proteger la retirada, el General Bernardino Caballero organizó la defensa, con niños que prefirieron morir antes que rendirse" (idem, p. 182). Durante a guerra destaca-se o altruísmo não só de López, mas também dos combatentes, entre eles crianças, que lutaram pela honra da pátria.

Em $1^{\circ}$ de março de 1870 , Solano López foi morto em Cerro Corá, nesta narrativa suas últimas palavras foram "muero con mi patria”. Essa expressão é recorrente não só em manuais escolares, mas em textos de historiadores paraguaios. Thomas Whigham ajuda a entender esta expressão:

As últimas palavras do Marechal foram relatadas com variações. Alguns escritores agregam ' e com a espada na mão!' ao familiar 'Morro com minha pátria'. Outros (incluindo a Centurión, por exemplo) registram as palavras como "Morro por minha pátria". A diferença entre as duas expressões é vista como essencial para muitos paraguaios para compreender o papel de López na história nacional (...). os idólatras do Marechal no século XX converteram suas palavras em algo canônico, indicado, quase como uma última comunicação com Deus. (WHIGHAM, 2012, p.473).

Como consequência da guerra a população foi dizimada, de acordo com o manual morreram 1.000.000 de pessoas, sendo que as 300.000 restantes eram, em sua maioria, crianças, mulheres e anciãos e alguns estrangeiros. Assim ficou a cargo das residentas a reconstrução do país e destaca-se seu estoicismo e grande valor. O capítulo termina citando alguns heróis da guerra dentre eles o General Bernardino Caballero descrito como El "Centauro de Ybycuí", héroe de cien batallas, lugarteniente del Mcal. López y reconstructor de la nacionalidad aniquilada" (idem, p.84). Vale lembrar, que Bernardino Caballero não foi apenas um dos principais aliados de Solano López, como também fundou o Partido Colorado. 
O manual do mesmo editorial destinado ao Segundo Curso da Etapa básica do Nível Médio tem a mesma estrutura e explica o governo dos López a partir dos mesmos pressupostos, sua diferença está na riqueza de adjetivos com que descreve os heróis da Pátria e na ampliação da lista de "obras de progresso" feitas naquela época.

Carlos López foi responsável pela lei que decreta o ventre livre, que deu início a liberdade dos escravos no Paraguai, mandou cunhar as primeiras moedas do país e "Continuó la misma política económica del Dr. Francia, el Estado paraguayo era el principal productor y exportador controlaba la economía nacional. Era un Estado mercantilista ." ( ALDERETE; TESSADA, 1989, p.248). Assim, "Se reconoce la época patriarcal de don Carlos como una de las más progresista y fecundas de nuestra historia." (idem, 251). Já seu filho "El Mcal. Francisco Solano López es considerado como el Primer Soldado, valiente y celoso defensor de la soberanía de nuestra patria y verdadero creador de la carrera de las armas. " (idem, p.251).

Solano López pode ser tomado também como um modelo de comportamento para o jovem em formação, na seção "Sabías que...?" São apresentadas outras informações biográficas sobre o herói nacional:

En su hogar aprendió la urbanidad, que distingue a un real caballero.

De Europa e Buenos Aires hacía traer libros que leía con curiosidad insaciable.

Demostraba predilección por la Geografía y la Historia y, sobre todo, por la Historia Militar.

Aprendió el francés y el inglés y se interesó por la lengua y literatura españolas.

Su alma y su vida estaban en el ejército, la vida militar le seducía con fuerza irresistible." (idem, p.253)

Após descrever as batalhas em que os paraguaios demonstraram "ousadia em suas ações”, "valor e heroísmo”. Um dos questionamentos feitos ao estudante é “¿De qué manera hoy, como miembro de tu familia, tu colegio y tu comunidad puedes servir a la patria?" (idem, p.265). Essa questão está de acordo com a concepção de educação dos autores desses manuais, e também representa a perspectiva do Ministério de Educación y Culto que, como citado anteriormente, entendia que os Estudos Sociais deveriam formar o jovem para que ele se tornasse um membro útil e efetivo na sociedade.

Nos manuais destinados ao nível médio a narrativa histórica tem um caráter moralizador, exalta-se não apenas os grandes feitos dos próceres da história paraguaia, mas 
também seus atributos pessoais. Enfatiza-se a maneira como a guerra interrompeu um período de progresso e que foram os aliados, e não Solano López, os responsáveis pela guerra. Outro fator importante é a valorização da coragem tanto dos soldados, quanto das mulheres e crianças na luta pela defesa da pátria contra o ataque dos inimigos estrangeiros, que através do tratado secreto, pretendiam submeter a nação.

O elogio ao militarismo que aparece nas narrativas pode ser entendido como um reflexo da importância que o serviço militar obrigatório alcançou na sociedade paraguaia durante o regime Stroessner. Em seu artigo “Volver para cumplir”. Los exiliados políticos y el Servicio Militar en Paraguay, Paola Riveros evidencia a importância do Serviço Militar Obrigatório para os jovens paraguaios que mesmo exilados por motivos políticos na Argentina voltavam para cumprir seu dever patriótico com a Nação. De acordo com Riveros organizou-se "un poderoso mecanismo que permitía la difusión de una serie de valores orientados hacia la aceptación acrítica a lo jerárquico, sacralizando algunos valores y formas de comunidad (la Patria)" (RIVEROS, 2012, p.09).

Ao longo dos trinta e cincos anos de ditadura a história da Guerra foi mobilizada, não apenas para disseminar os valores considerados úteis para "el saber vivir socialmente" (MINISTERIO DE EDUCACIÓN Y CULTO, 1973, p. 102) mas também como instrumento de propaganda do regime. O dia 1 de março, no qual se comemora o Día de los Heroes, tornou-se uma importante festa cívica na qual as instituições educativas tinham papel fundamental.

\section{Imagem 1}

Con unción patriótica, recordóse ayer al Mcal. López 


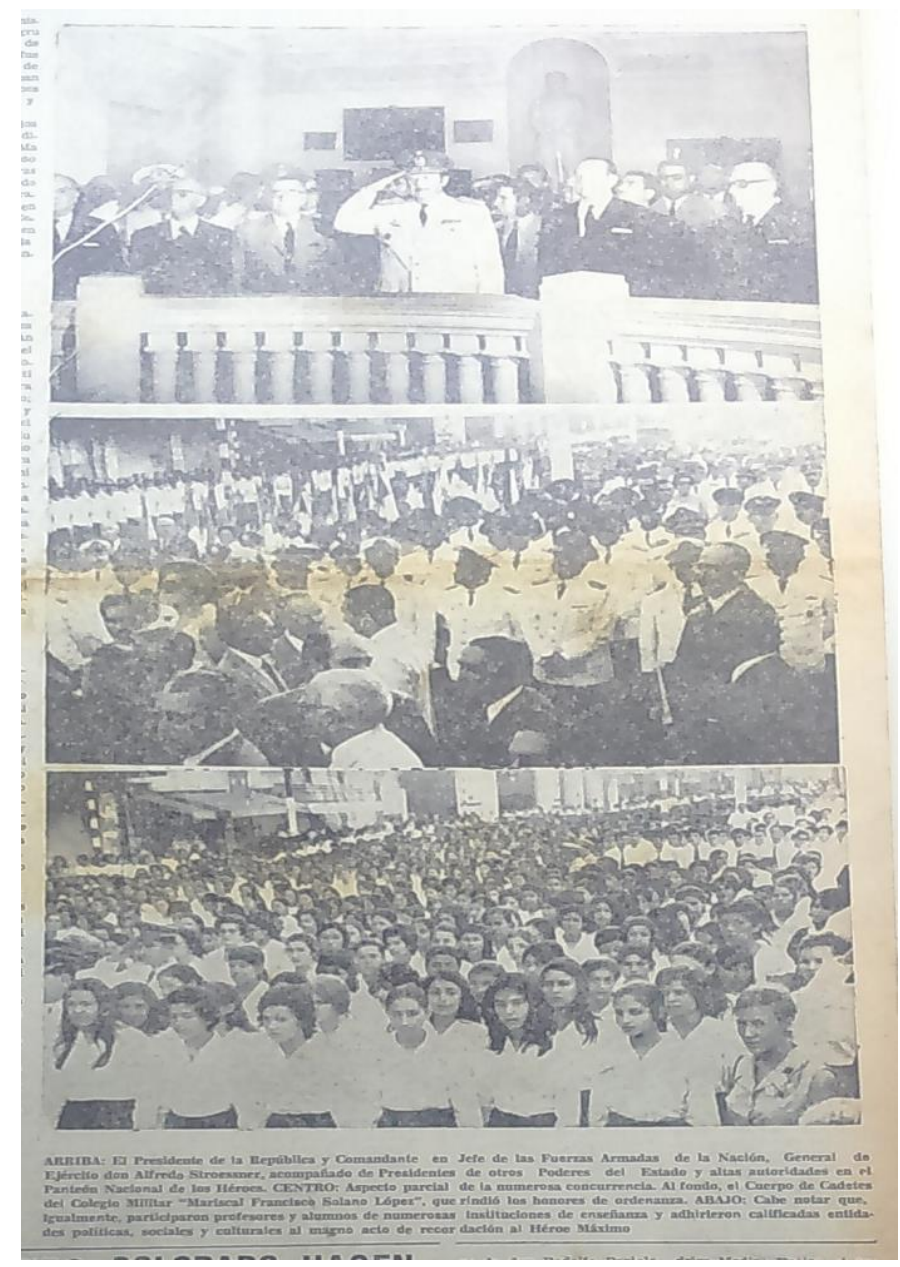

Fonte: Diário Patria, 02 de março de 1973.

Na legenda lê-se:

ARRIBA:El presidente de la Republica y comandante en jefe de las Fuerzas Armadas de la Nación, General de ejército don Alfredo Stroessner, aconpañado de presidentes de otros poderes del Estado y altas autoridades en el Panteón Nacional de los Heroes. CENTRO: aspecto parcial de la numerosa concurrencia. Al fondo el Cuerpo de Cadetes del Colegio Militar Mariscal Francisco Solano López, que rindió los honores de la ordenanza. ABAJO: cabe notar que, igualmente, participaron profesores y alumnos de numerosas instituciones de ensañanza y adhirieron calificadas entidades politicas, sociales y culturales al magno acto de recordación al Heroe Maximo. 
Imagem 2: Fue honrada la memoria del Mcal. F. S. López en el Día de los Héroes

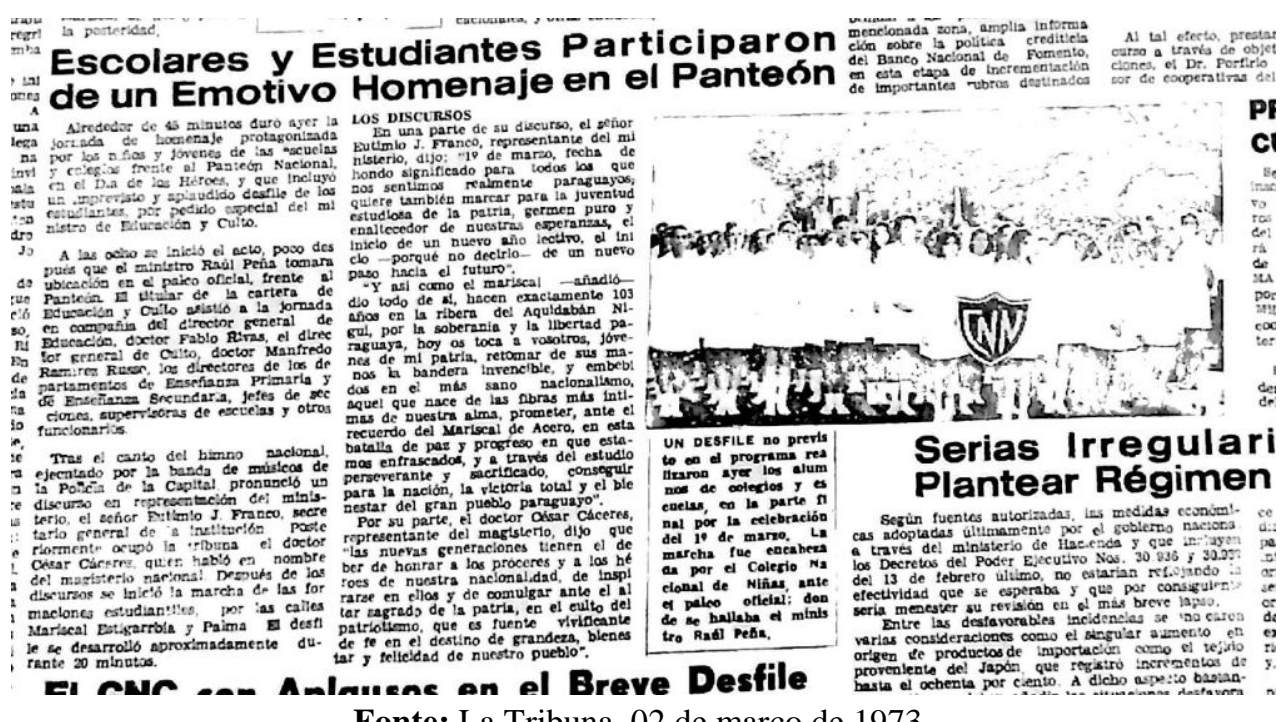

Fonte: La Tribuna, 02 de março de 1973.

Além do Día de los Heroes, no qual se rendiam homenagens ao heróis da "epopeya nacional", isto é da Guerra de la Triple Alianza, o calendário escolar era marcado por outras comemorações cívicas, como o nascimento do Heroe Maximo de la nacionalidade (Solano López) e os desfiles da "Juventude estudiosa." (SOLER et. Al., 2015).

\section{Considerações finais}

Tanto os manuais destinados ao ensino primário, editados antes da reforma de 1973, quanto aqueles direcionados ao nível médio e posteriores a reforma apesar das diferenças no que concerne à diagramação, à estrutura narrativa e aos modos de abordagem do conteúdo apresentam os López como próceres da nação paraguaia e seu governo como tempo de progresso. Vale lembrar que que uma das estratégias de Stroessener para consolidar-se no poder era convencer o povo de que viera para trazer a paz, além de prometer o progresso da nação, pondo fim as constantes lutas internas. Doratioto ressalta a importância da figura de López durante o regime Stroessner, "sob as três décadas de ditadura de Alfredo Stroessener o lopizmo tornou-se onipresente apoiado pelo Estado, e intelectuais que ousaram questionar a glorificação de Solano López foram perseguidos e, mesmo exilados" (DORATIOTO, 2002, p. 86) Ademais, Stroessner disseminava junto ao povo a ideia que iria reconduzir a pátria a um lugar de destaque no concerto das nações, de modo a continuar as obras dos López e também 
de Francia. Assim a narrativa histórica é utilizada de modo a justificar o regime, tornando o lopizmo um dos elementos fundamentais da propaganda stronista.

Desse modo, a história da guerra apresentada nesses manuais adquire um caráter ideológico e uma perspectiva eminentemente política, pois não está relacionada apenas com a formação de uma identidade nacional, mas com um plano de governo conservador, autoritário e nacionalista, que promove um culto aos heróis da pátria e também a pessoa de Stroessner que "siempre se consideró el auténtico heredero de los 'grandes del pasado"'(GONZÁLEZ, 2002, p.164).

Berstein (1988) ressalta que a cultura política "se inscreve no quadro das normas e dos valores que determinam a representação que uma sociedade faz de si mesma, do seu passado e do seu futuro"(BERSTEIN, 1988, p.353), esse autor compreende que as culturas políticas possuem diversos meios de difusão, que não são propriamente políticos, como a escola, por exemplo. Nessa perspectiva pode-se pensar que o regime de Stroessner apoiado no partido colorado e nas forças armadas foi um difusor de uma cultura política nacionalista, que incidiu sobre as práticas escolares por meio da imposição de reformas e decretos que tinham por objetivo construir e/ou modificar valores, comportamentos e práticas no seio da sociedade paraguaia.

\section{Referências Bibliográficas e Documentais}

\section{A- Fontes documentais}

ALDERETE, Elisa R. Dominguez, TESSADA, Mirtia Caballero de. Estudios Sociales Primer curso - etapa básica del nivel medio. Ministerio de Educación y Culto - división editorial educativa, Ano:1989.

ALDERETE, Elisa R. Dominguez, TESSADA, Mirtia Caballero de. Estudios Sociales Segundo curso - etapa básica del nivel medio. Ministerio de Educación y Culto - división editorial educativa, Ano:1989.

ALDERETE, Elisa R. Dominguez, TESSADA, Mirtia Caballero de. Estudios Sociales Guia didáctica - etapa básica del nivel medio. Ministerio de Educación y Culto - división editorial educativa, Ano:1989.

MINISTERIO de Educación Y Culto. Programa de desarrollo educacional. Innovaciones educacionales. Paraguay, 1973 
Paraguay, 1983. Programa de Estudio - professorado de educación primaria. Asunción Plan de desarrollo educacional 1969-1980. Tomo II. Paraguay,1969 . Diagnóstico del sistema educativo. Tomo I. Paraguay,1969.

Jornais:

Diario Pátira: 02 de março de 1973

01 de março de 1976

Diário La Tribuna: 02 de março de 1973

B- Bibliográficas

ARCE, Omar Díaz de. O Paraguai contemporâneo (1925-1975). In: CASANOVA, Pablo Gonzáles. América Latina: História de meio século. Brasília: Editora Universidade de Brasília, 1988.

ARECES, Nidia R. De la independencia a la Guerra de la Tríple Alianza (1811-1870). IN. TELESCA, Ignacio. História del Paraguay. Paraguay: Taurus, 2014.

BERSTEIN, Serge. A Cultura Política. In: RIOUX \& SIRINELLI (Org.) Para uma História Cultural. Lisboa: Estampa, 1988.

BREZZO, Liliana M. El Paraguay en cinco momentos historiográficos: retos y perspectivas. In: CASAL, J; WHIGHAM, T. (Orgs.). Paraguay: El nacionalismo y la Guerra - Actas de las primeras jornadas de Historia del Paraguay em la Universidad de Montevideo. Asunción: Servilibro, 2009

CARDOZO, Efraím. Breve Historia del Paraguay. Asunción: Servilibro, 2011.

CARRERAS, J. J; FORCADELL, C. Usos públicos de la historia. Madrid: Prensas Universitarias de Zaragoza. Marcial Pons. 2003.

CARVALHO, José Murilo de. Forças armadas e política no Brasil. Rio de Janeiro: Jorge Zahar Ed, 2005. p.179

DORATIOTO , Francisco. Maldita Guerra: nova história da Guerra do Paraguai. São Paulo: Companhia das Letras, 2002

DOURADO, Maria Teresa Garritano. A história esquecida da Guerra do Paraguai: fome, doenças e penalidades. 2010. 222 f. Dissertação ( Mestrado em História). Universidade de São Paulo. São Paulo, 2010.

FAGUNDES, Luciana, Pessanha. Construindo pontes entre olhares: os usos políticos do passado. In: III Simpósio ILB. Itinerários da Pesquisa Histórica: Métodos, Fontes e Campos Temáticos, 2010, Mariana. Anais do III Simpósio Impérios e Lugares no Brasil, 2010. 
GONZÁLEZ VERA ,Myrian. Fecha Feliz en Paraguay. Los festejos del 3 de noviembre, cumpleaños de Alfredo Stroessner. IN: JELIN, Elizabeth. Las conmemoraciones: las disputas en las fechas "in-felices”. Espanha: Siglo veinteuno, 2002.

HORAK, Carmen Quintana de. La educación escolar en el Paraguay: apuntes para una Historia. Asunción: Centro de Estudios Paraguayos Antonio Guasch. s/d.

IZECKSOHN, Vitor. A Guerra do Paraguai. IN. GRINBERG, Keila. SALLES Ricardo.(Orgs.). O Brasil Imperial - Vol II - 1831-1889. Rio de Janeiro: Civilização Brasileira, 2009. P. 385-424.

MAESTRI, MÁRIO. A Guerra Contra o Paraguai: História e Historiografia: da instauração à restauração historiográfica [1871-2002]. La Guerra del Paraguay: historiografías, representaciones, contextos. Anual del CEL, Buenos Aires, 3-5 de noviembre de 2008, Museo Histórico Nacional, Defensa 1600. Disponível em: https://nuevomundo.revues.org/55579\#ftn12

MORAES, Ceres. Paraguai: a consolidação da ditadura Stroessner (1954-1963). Porto Alegre: EDIPUCRS, 2000.

MOTA, Carlos Guilherme. História de um silêncio: a guerra contra o Paraguai (1864-1870) 130 anos depois. Estudos Avançados, n. 24. 1995. P. 244.

PINEDA, Oscar. Breve Historia de la Educación en el Paraguay. Asunción: Servilibro, 2012.

RIVEROS, Paola Fabiana. "Volver para cumplir". Los exiliados políticos y el Servicio Militar en tParaguay. In: Jornadas de trabajo Exilios politicos del cono sur en el siglo XX. . La Plata sepiembre de 2012 http://jornadasexilios.fahce.unlp.edu.ar

SOLER, Lorena et al. El régimen stronista y su incidencia en la configuración y las prácticas escolares (1954-1970). Cuadernos Chilenos de Historia de la Educación. Ano 3, n.4. p. 1033. 2015

SOLER, Lorena. Claves Históricas Del Régimen Político En Paraguay. López Y Stroessner Diálogos - Revista do Departamento de Historia e do Programa de Pós-Graduação em História, vol. 11, núm. 1-2, p. 19-54, 2007.

WHIGHAM, Thomas. La guerra de la Triple Alianza: danza de muerte y destrucción. Asunción: 